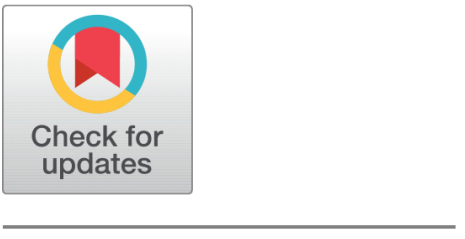

open acCess

Received: 13.12 .2020

Accepted: 14.01 .2021

Published: 28.01 .2021

Citation: Pareek D, Sengar P (2021) Decrement of secondary gamma radiation flux during lunar eclipse June 16, 2011. Indian Journal of Science and Technology 14(3): 245-250. https://doi.org/ 10.17485/IJST/v14i3.2232

* Corresponding author.

Tel: 9413954886

deven.pareek69@gmail.com

Funding: None

Competing Interests: None

Copyright: @ 2021 Pareek \& Sengar. This is an open access article distributed under the terms of the Creative Commons Attribution License, which permits unrestricted use, distribution, and reproduction in any medium, provided the original author and source are credited.

Published By Indian Society for Education and Environment (iSee)

ISSN

Print: 0974-6846

Electronic: 0974-5645

\section{Decrement of secondary gamma radiation flux during lunar eclipse June 16, 2011}

\author{
Devendra Pareek $^{1 *}$, Pallavi Sengar ${ }^{1}$ \\ 1 Department of Physics, Bhupal Nobles' University, Udaipur, 313001, India. Tel.: 9413954886
}

\section{Abstract}

The lunar eclipse at Udaipur $\left(27^{\circ} 43^{\prime} 12.00^{\prime \prime} \mathrm{N}, 75^{\circ} 28^{\prime} 48.01^{\prime \prime} \mathrm{E}\right)$, India was experimentally observed on June16, 2011 using ground based Nal (TI) Scintillation detector. We interpret such decrement of secondary gamma radiation flux (SGRF) on the basis of obstruction effect produced by Earth and Moon during lunar eclipse on radiation. Objective: To observe secondary gamma radiation flux during lunar eclipse day on comparison to pre and post eclipse days. Methods: For this experimental study we used ground based $\mathrm{Nal}$ (TI) Scintillation detector. The data files were stored in computer for thirty minutes duration from 1.00 AM to 2.00 AM (Indian Time) on pre-eclipse normal days June 14 and 15, 2011 as well as on post eclipse normal day June 17 and also on eclipse day June 16, 2011. Finding: The analyzed data reveal significant decrement of secondary gamma radiation flux (SGRF) on lunar eclipse day about $6 \%$ on comparison to pre and post lunar eclipse days. Novelty: In this experimental study first time we reported about $6 \%$ decrement of secondary gamma radiation flux on lunar eclipse day on comparison to pre and post lunar eclipse days.

Keywords: Lunar eclipse; cosmic radiation; reflected solar radiation; secondary gamma radiation; obstruction effect by Earth and Moon

\section{Introduction}

Charged particles cosmic radiation travels at nearly the speed of light and coming towards the Earth from all directions. Composition of such radiation is about $89 \%$ of these nuclei are protons, $10 \%$ of helium, and $1 \%$ of others heavier elements ${ }^{(1)}$. There is another class of radiation called solar radiation (SR) corresponded with energetic events on the sun. The cosmic radiation (CR) almost isotropically distributed and propagates through space while arriving on the Earth ${ }^{(2)}$. When both radiations reach towards the earth atmosphere and strikes with atoms of the upper atmosphere of the Earth then there is production of "secondary" radiation. This secondary radiation has electromagnetic component which consist of gamma radiation, electrons. Produced secondary radiation can be detected using appropriate detector on ground ${ }^{(3,4)}$.

On $15^{\text {th }}$ and $16^{\text {th }}$ June 2011 Lunar eclipse was witnessed over much of Europe, much of Asia, Australia, Africa, South America, Pacific, Atlantic, Indian Ocean and Antarctica as shown in Figure 1. 


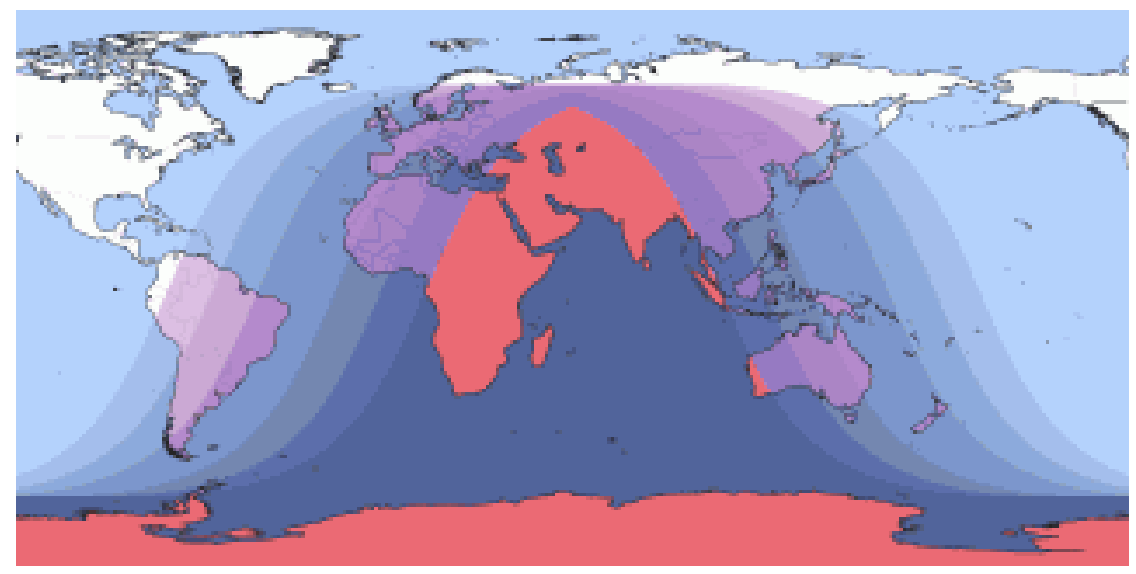

Fig 1.

Many scientist groups AnandaRao J.N. et al. ${ }^{(5)}$, Bhaskar et al. ${ }^{(6)}$, Bhattcharya et al. ${ }^{(7)}$, Bhattcharya et al. ${ }^{(8)}$, Chintalapudi S. N. ${ }^{(9)}$, Kandemir G. et al. ${ }^{(10)}$, Nayak. et al. ${ }^{(11)}$, Pareek et al. ${ }^{(12)}$, Abdullah Al Zaman MD et al. ${ }^{(13)}$ studied of radiation flux during solar eclipses.

Pareek et al. ${ }^{(14)}$ observed the variation of secondary radiation flux during lunar eclipse.

With the fact that during different celestial events happening in sky, modulate terrestrial secondary flux of cosmic and solar radiation, ground based experimentally study was conducted to see the effect of lunar eclipse (June 16, 2011) on secondary gamma radiation flux using scintillation detector.

\section{Experimental Set-up and Observations}

In this experimental study scintillation detector of Model 802 (Figure 2), make: Canberra Genie 2000 used to detect the secondary solar gamma radiation. Photo multiplier tube (PMT) Model 2007P coupled with NaI (Tl) crystal $50 \mathrm{~mm}$ thick and $44.5 \mathrm{~mm}$ in diameter with high tension voltage supply model 3102D of 1100 Volts DC was used. Using amplifier Model 2022 negative signal of about 0.5 Volts was amplified to 5 Volts positive pulse. Finally, this signal was fed to multi-channel analyzer 1024 energy channels. This counter system was used to collect the counts as a function of time. In India lunar eclipse began from June 15on 11.53 PM and ended June 16 on 3.32 AM. Maximum eclipse was on 1.43 AM in India. The energy calibration was observed to be $2.0 \mathrm{keV}$ per channel using standard radioactive sources $\mathrm{Cs}^{137}$. Data were taken from 1.00AM to 2.00 AM at Udaipur, India on June 14, 15, 16 and 17, 2011. Normal days were on June 14, 15 and 17 and on June 16, 2011 there was lunar eclipse day. In this whole experimental study the detector was pointed towards moon.

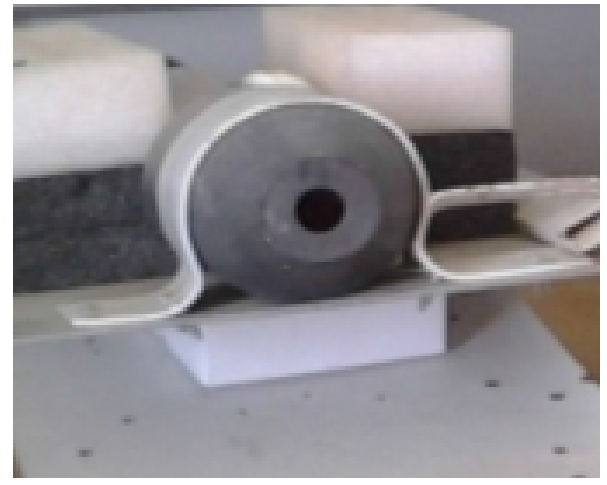

Fig 2. 


\section{Analysis and Results}

As depicted in the panels of Figure 3 the energy spectrum of SGR flux on pre-eclipse days $\left(14^{\text {th }}, 15^{\text {th }}\right.$ June), eclipse day $\left(16^{\text {th }}\right.$ June) and post eclipse day ( $17^{\text {th }}$ June) in the energy range between $1 \mathrm{keV}-2200 \mathrm{keV}$ were taken from 1.00 AM.-2.00 A M. of duration of half an hour integrated data files.
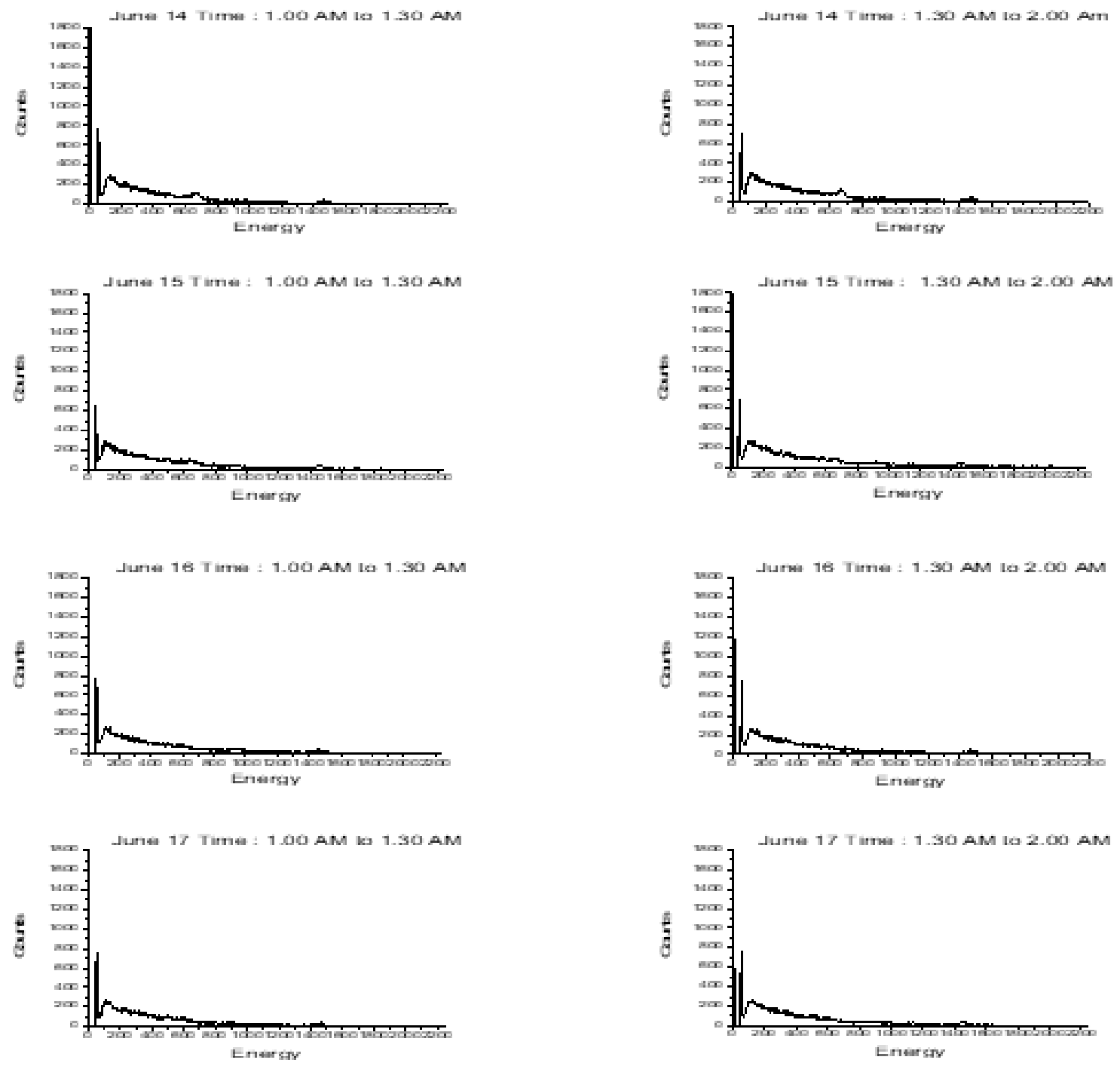

Fig 3. (Panel of energy spectrum of pre-eclipse days, lunar eclipse day, and post eclipse day)

Table 1 represents the integrated counts on the pre, post and onlunar eclipse days of secondary gamma radiation flux from time $1.00 \mathrm{AM}$ to $2.00 \mathrm{AM}$ 
Table 1.

\begin{tabular}{llll}
\hline Sr. No. & Date & Integrated Counts & \\
\hline & Time & 1.00 AM-1.30 AM & 66563 \\
\hline 1 & 14 (Pre-Eclipse Day) & 65351 & 62452 \\
2 & 15 (Pre-Eclipse Day) & 62229 & 58978 \\
3 & 16 (Lunar Eclipse day) & 58441 & 59451 \\
4 & 17 (Post Eclipse Day) & 59067 & AM \\
\hline
\end{tabular}

Using Table 1 we made Figure 4 between date and integrated counts on pre-eclipse days ( $14^{\text {th }}, 15^{\text {th }}$ June), eclipse day $\left(16^{\text {th }}\right.$ June) and post eclipse day (17 $7^{\text {th }}$ June) from 1.00 AM.-1.30 and 1.30 AM - 2.00 A M. of duration of half an hour integrated data files.

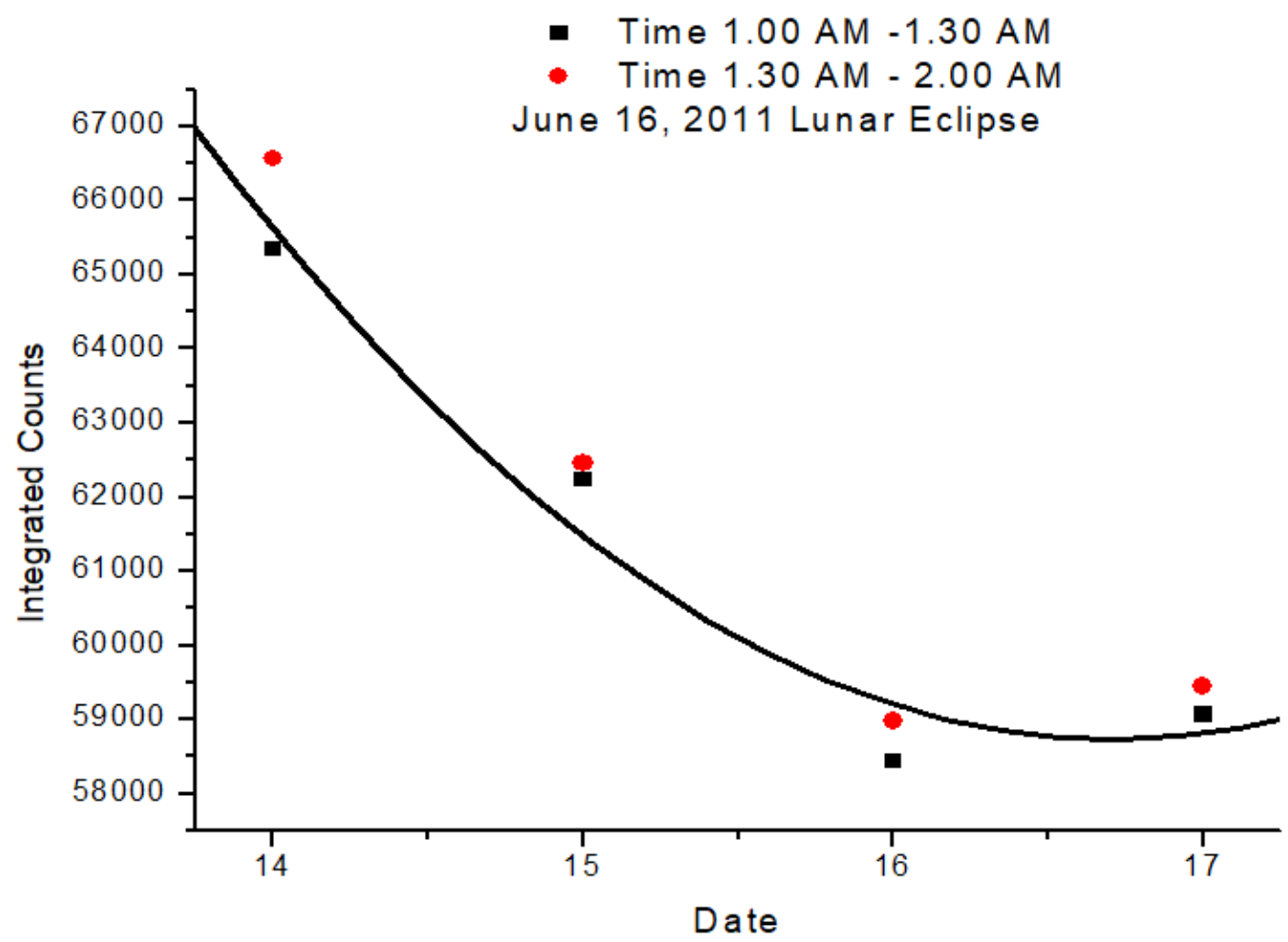

Fig 4.

The maximum eclipse on date June 16 was on the time $1.43 \mathrm{AM}$ so to see better result we added half an hour of data files of 1.00 AM -1.30 AM and 1.30 AM - 2.00 AM and it is representing in Table 2.

Table 2.

\begin{tabular}{lll}
\hline Sr. No. & Date & Integrated Counts \\
\hline & & Time 1.00 AM- 2.00 AM \\
\hline 1 & 14 (Pre-Eclipse Day) & 131914 \\
2 & 15 (Pre-Eclipse Day) & 124681 \\
3 & 16 (Lunar Eclipse day) & 117419 \\
5 & 17 (Post Eclipse Day) & 118518 \\
\hline
\end{tabular}

Using Table 2 we made Figure 5 between date and integrated counts on pre-eclipse days ( $14^{\text {th }}, 15^{\text {th }}$ June), eclipse day $\left(16^{\text {th }}\right.$ June) and post eclipse day ( $17^{\text {th }}$ June) from 1.00 AM.-2.00 A M. of duration of an hour integrated data files. 


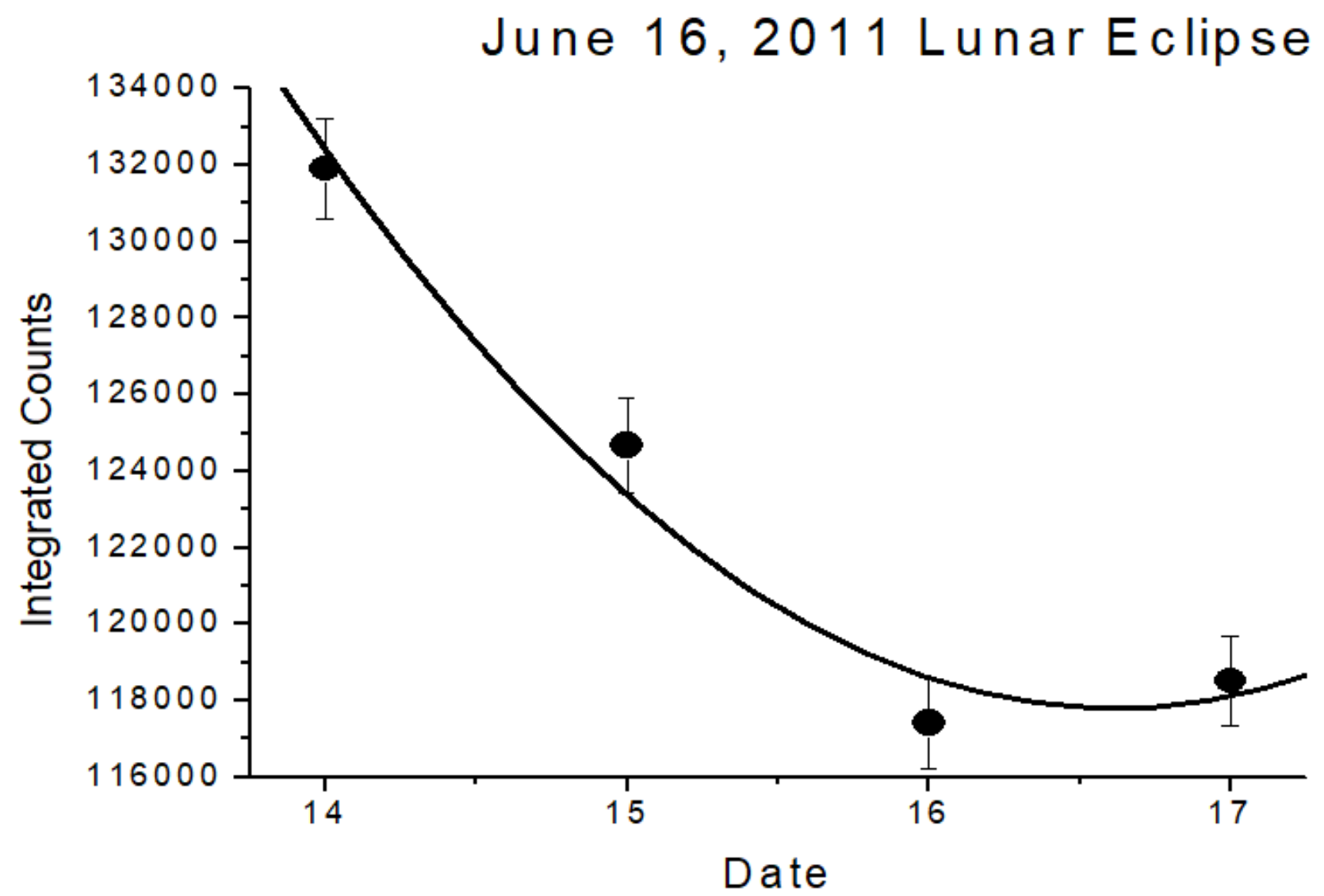

Fig 5.

Table 2 and Figure 5 clearly showed that on the pre-eclipse days 14 and 15 the integrated counts were 131914, 124681 respectively. On the lunar eclipse day 16 the counts were 117419 . On the post eclipse day 17 integrated counts were 118518 . When average of integrated counts of all normal days 14, 15, and 17 were taken then integrated counts were about 125037. Therefore, on comparison to this average count with lunar eclipse day16 June the integrated counts were decreased by 7618 . To see the variation in secondary gamma radiation on the lunar eclipse day we used the following formula:

$$
\% \text { of variation }=\frac{\text { Average counts of normal days counts on eclipse day }}{\text { Average counts of normal days }} X 100
$$

Using this formula on the lunar eclipse day about $6 \%$ reduction in the counts of SGR flux on comparison to average counts of normal days.

\section{Discussion}

In solar eclipse studies various scientist groups observed variation of radiation flux. Now a day's Secondary radiation flux variations during solar and lunar eclipses attracted attention.

Ananda Rao J.N. et al. (1967); Bhattacharyya A. et al. (1997); Kandemir et al. (2000); Bhattacharya. et al. (2010); Nayak et al., (2010); and Bhaskar et al. (2011) studied of radiation flux during solar eclipses.

Abdullah Al Zaman MD et al. also studied of radiation flux during different types of Solar eclipses from 1990 to 2017.

Chintalapudi et al. (1997) observed decrease in radiation flux. He explained due to blocking of the Sun by the Moon during solar eclipse variation of radiation reported.

During Partial Solar Eclipse of 4th January 2011 at Udaipur, India Pareek et al. (June, 2013) also observed decrement of secondary radiation flux and gave the reason that during eclipse, the galactic cosmic radiations (GCR) and solar energetic 
particles (SEP) are obstructed by the moon. Solar eclipse occurred when Moon comes in between Sun and Earth. Therefore, the Moon produced obstruction effect on solar and cosmic radiation.

Pareek et al. (May 2013) reported of variation of secondary cosmic gamma ray flux near $2.57 \mathrm{MeV}$ energy during April 4, 1996 Total Lunar Eclipse and at energies near 1.31 MeV, 1.618 MeV, 2.57 MeV during July 16, 2000 Total Lunar Eclipse.

The studies of solar and lunar eclipses inspired us to conduct experimental study to observe secondary gamma radiation flux during lunar eclipse June 16, 2011.

In this present experimental study, we observed decrement of secondary radiation during Lunar eclipse. Lunar eclipse occurred when Earth comes between Sun and Moon. Therefore, in this case Earth and Moon produced obstruction effect on cosmic and reflected solar radiation during lunar eclipse day on comparison to normal days. Therefore, we reported drop in secondary gamma radiation flux about 6\% during lunar eclipse June16, 2011 using ground based $\mathrm{NaI}$ (Tl) Scintillation detector.

\section{Conclusion}

During lunar eclipse, the Earth and Moon cuts radiations (CR and reflected solar radiation). Therefore, less radiations incident on the atmosphere of the earth, and we got less secondary gamma radiation during lunar eclipse day (about $6 \%$ cut) in comparison with the average counts of normal days.

\section{Acknowledgments}

The authors wish to thank anonymous referees.

\section{References}

1) Longair MS. High energy Astrophysics. 2nd ed. and others, editor;Cambridge University Press. 1992.

2) Fulks GJ. Solar modulation of galactic cosmic ray electrons, protons, and alphas. Journal of Geophysical Research. 1975;80(13):1701-1714. Available from: https://dx.doi.org/10.1029/ja080i013p01701.

3) Chilingarian A, Daryan A, Arakelyan K, Hovhannisyan A, Mailyan B, Melkumyan L, et al. Ground-based observations of thunderstorm-correlated fluxes of high-energy electrons, gamma rays, and neutrons. Physical Review D. 2010;82(4). Available from: https://dx.doi.org/10.1103/physrevd.82.043009.

4) Kodama M. Ground Albedo Neutrons Produced by Cosmic Radiations. Physical Society of Japan. 1983;52:1503-1504.

5) Anandarao J. Variation in the background counting rate at Tirupati during the periods of solar and lunar eclipses. Physics Letters A. 1967;25(2).

6) Bhaskar A, Purohit A, Hemalatha M, Pai C, Raghav A, Gurada C, et al. A study of secondary cosmic ray flux during the annular eclipse of 15 . Astropart Phys. 2010;35:223-229.

7) Bhattacharyya A, Biswas S, Chatterjee BK, Das M, Das PK, Das TK, et al. Variation of gamma ray and particle fluxes at the sea level during the total solar eclipse of 24 october. Astro Space Sci. 1997;250:313-326.

8) Bhattacharya R, Roy M, Biswas M, Guha R, Bhoumick A. Cosmic ray intensity and surface parameters during solar eclipse on 22 July 2009 at Kalyani in West Bengal. Curr Sci. 2010;98:1609-1614.

9) Chintalapudi SN, Ghosh V, Krishna JB, Verman JR, Prakash H, Pal G, et al. Gamma and X ray measurements during Total Solar Eclipse on October 24, 1995 at Diamond Harbour, Kodaikanal. Obs Bull. 1995;13:225-234.

10) Kandemir G. the Last Total Solar Eclipse of the Millennium in Turkey, ASP Conference Series. 2000.

11) Nayak PK, Gupta SK, Jain A, Mazumdar I, Raha S, Saha SK, et al. A study of the $\gamma$-ray flux during the total solar eclipse of 1 August 2008 at Novosibirsk, Russia. Astroparticle Physics. 2010;32(6):286-293. Available from: https://dx.doi.org/10.1016/j.astropartphys.2009.09.006.

12) Pareek D, Jaaffrey SNA, Talesra KP, Yadav R, Ameta S. Experimental study of Variation of Secondary Cosmic Gamma Ray Flux and Energy during Partial Solar Eclipse of 4th January 2011 at Udaipur, India. Research journal of physical sciences. 2011;1(5):22-30.

13) Zaman MDAA, Monira NJ. Variation of Cosmic Ray Intensity during different Types of Solar Eclipses from 1990 to 2017 (August). J Space Explor. 2017;6(3):135. Available from: https://www.tsijournals.com/articles/variation-of-cosmic-ray-intensity-during-different-types-of-solar-eclipses-from1990-to-2017-august.pdf.

14) Pareek D, Jaaffrey SNA. Experimental Study of Variation of Secondary Cosmic Gamma Ray Flux during Total Lunar Eclipse April 4, 1996 and July 16, 2000. Research journal of physical sciences. 2013;1(4):22-27. 